\title{
Airway smooth muscle in health and disease; methods of measurement and relation to function
}

\author{
A. James, N. Carroll
}

\begin{abstract}
Airway smooth muscle in health and disease; methods of measurement and relation to function. A. James, N. Carroll. (C) ERS Journals Ltd 2000.

ABSTRACT: Smooth muscle is present and probably functional in the airways in utero and increases in absolute area during growth with little further change during adulthood. It encircles the entire airway below the level of the main bronchus, in a roughly circular orientation, except at high lung volumes. It occupies relatively more of the airway wall in the peripheral airways, reaching a maximum in the membranous bronchioles.

Measurement of smooth muscle area in the airway wall is confounded by clinical classification of cases, methods of tissue retrieval and preparation, staining and orientation of sections, magnification, image analysis and statistical methods of comparison between groups.

Airway smooth muscle area is pathologically increased in inflammatory conditions of the airways such as chronic obstructive pulmonary disease, in relation to airways obstruction, and asthma, in relation to severity and airway size (between 25 and $250 \%$ compared with control cases). It is increased in sudden infant death syndrome, but there are few studies in other conditions such as bronchiectasis. In asthma, smooth muscle must shorten (not necessarily to an abnormal degree) for the structural abnormalities of the airway to manifest as excessive airway narrowing.

Not surprisingly there is renewed interest in the relationships between the mechanical and contractile properties of smooth muscle, parenchymal properties and lung volume and how these interact to determine smooth muscle length. The relative importance of smooth muscle area and mechanical properties, altered airway structure and airway inflammation in disease are yet to be determined.

Eur Respir J 2000; 15: 782-789.
\end{abstract}

Dept of Pulmonary Physiology, Sir Charles Gairdner Hospital, Nedlands, Western Australia, Australia.

Correspondence: A. James

Dept of Pulmonary Physiology

Sir Charles Gairdner Hospital

Hospital Avenue

Nedlands 6009

Western Australia

Australia

Fax: 61893462034

Keywords: Morphology

morphometry

structure

Received: January 12000

Accepted after revision January 122000
Airway smooth muscle is present in the bronchial tree of most vertebrates studied including the pig, ox, cat, dog, rabbit and guinea-pig, although the exact function of the smooth muscle is not clear. In this paper, comments will be confined to studies in man. In an extensive review, MACKLIN [1] speculated that possible functions of airway smooth muscle might include control of airflow distribution, alterations in the size of the dead space, assisting contraction of the lung, expelling air or foreign material, controlling airway calibre during different phases of respiration and allowing variations in the compliance of the airway wall to match functions such as tidal breathing, deep breathing, and coughing or forced expiration. In this review, the term "central airways" refers to cartilaginous airways, which in most cases means lobar or segmental bronchi, ranging from an internal diameter of $11 \mathrm{~mm}$ (internal perimeter $35 \mathrm{~mm}$ ) for main bronchi to approximately $1.3 \mathrm{~mm}$ (perimeter $4 \mathrm{~mm}$ ) in small intraparenchymal bronchi. "Peripheral airways" refers to airways without cartilage, from large membranous bronchioles of internal diameter $1.3 \mathrm{~mm}$ (internal perimeter $4 \mathrm{~mm}$ ) to respiratory bronchioles of approximately $0.3 \mathrm{~mm}$ diameter $(1 \mathrm{~mm}$ perimeter). Unless otherwise stated, airway diameters and perimeters refer to internal (luminal) dimensions.

\section{Normal anatomy}

Airway smooth muscle was first described in detail by REISSESSEN [2] in 1822. A hand-held magnifier was used to examine the muscle in the bronchial tree to the level of the membranous bronchiole and it was inferred that the smooth muscle continued to the most peripheral parts of the lung. This and other descriptive studies [1, 3-5] showed that airway smooth muscle is present in the central and peripheral airways, relatively more prominent in the peripheral airways, more transverse in central airways and slightly more longitudinal in peripheral airways, and arranged in a helical or geodesic pattern which is more apparent in peripheral airways and when the lung is fully inflated.

Previous articles in this Series: No. 1. S.J. Gunst, D.D. Tang. The contractile apparatus and mechanical properties of airway smooth muscle. Eur Respir J 2000; 15: 600-616. 


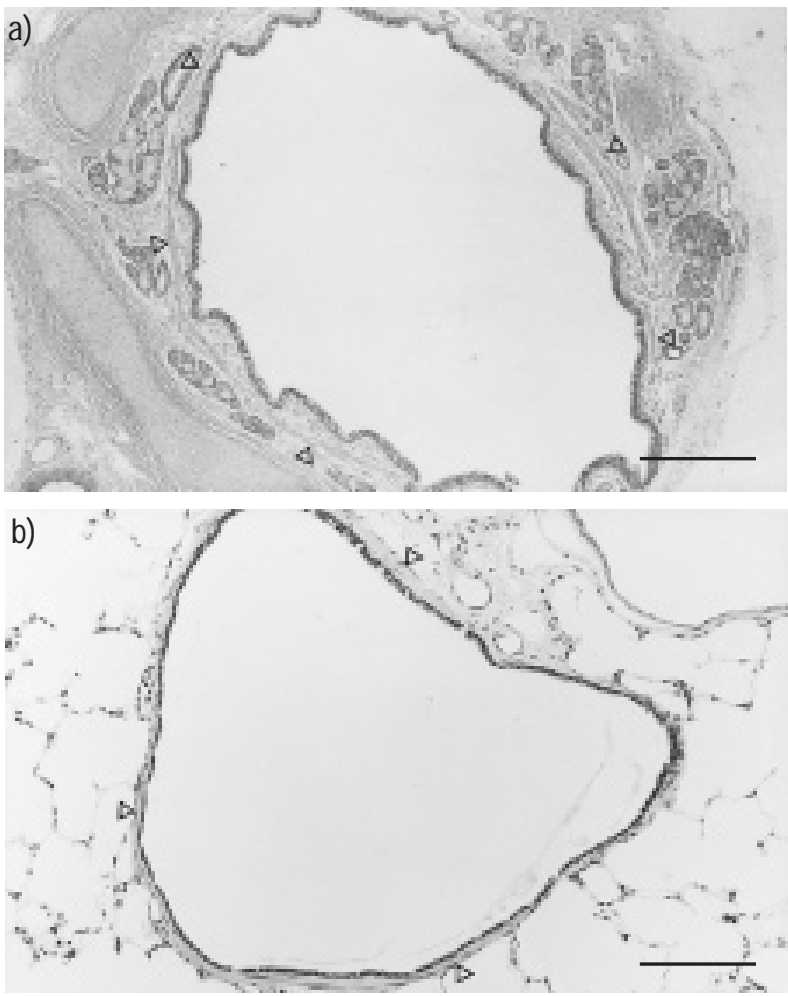

Fig. 1. - a) A cartilaginous airway with prominent bronchial glands from a nonasthmatic case. The airway smooth muscle (arrowheads) can be seen as a discontinuous circular band in the submucosa. There is some shortening of the muscle, suggested by the folding of the epithelial layer. b) A membranous bronchiole with a thin wall, largely made up of smooth muscle (arrowheads) from a nonasthmatic case. (Internal scale bars $=2 \mathrm{~mm}$ (a) and $0.25 \mathrm{~mm}$ (b).)

\section{Distribution within bronchial tree}

Numerous studies [3, 6-10] have shown that the airway smooth muscle occupies relatively more of the airway wall in the peripheral airways compared with the central airways (fig. 1). Matsuba and Thurlbeck [7] found that the percentage of the airway wall area occupied by smooth muscle in central and peripheral airways was 2.6 and 14 in adults and 2.8 and 10 in children, respectively. These values for central airways are similar to those found in other studies: HaLE et al. [11] 2.5\%, DunNiLl et al. [12] $4.5 \%$ (range $2-11 \%$ ), and TAKIZAWA and ThuRLBECK [6] $2.5 \%$. SobOnya [13] found a similar trend in relation to airway size even when comparing lobar with segmental airways. SAETTA et al. [14] studied small airways with a mean diameter (perimeter) of $0.89 \mathrm{~mm}(2.8 \mathrm{~mm})$ and found that smooth muscle occupied $18 \%$ of the wall area. EBINA et al. [10] showed that the thickness of the airway smooth muscle, relative to the airway diameter, increased towards the periphery, although the thickness varied 10fold within the same groups of airways. In absolute terms, the amount of airway smooth muscle is lesser in the peripheral airways. A number of studies [8, 9, 15-17] have standardized the amount of smooth muscle in the airway wall by measuring the total cross-sectional area of smooth muscle seen on a transverse section of the airway and dividing it by the length of the basement membrane (the perimeter of the airway) since this is independent of the degree of airway smooth muscle contraction and lung in-
Table 1. - Airway smooth muscle thickness in large and small airways in adults

\begin{tabular}{lcc}
\hline Bronchi & $\begin{array}{c}\text { Basement } \\
\text { membrane } \\
\text { perimeter } \mathrm{mm}\end{array}$ & $\begin{array}{c}\text { Airway smooth muscle } \\
\text { thickness } \mathrm{mm}^{2} \cdot \mathrm{mm} \\
\text { basement membrane }\end{array}$ \\
\hline Main & $25-35$ & $0.05(0.015-0.06)$ \\
Lobar & $10-25$ & $0.04(0.031-0.05)$ \\
Segmental/ & $6-15$ & $0.02(0.005-0.03)$ \\
$\quad$ subsegmental & & \\
Membranous & $4-6$ & $0.01(0.005-0.023)$ \\
Large & $1-4$ & $0.005(0.003-0.01)$ \\
Small & &
\end{tabular}

flation $[18,19]$. Expressing the amount of smooth muscle in this way, as mean thickness in relation to airway perimeter, allows a ready comparison between studies. As a generalization, the mean thickness of smooth muscle (in $\mathrm{mm}^{2} \cdot \mathrm{mm}$ basement membrane $\mathrm{e}^{-1}$ ) in adults is summarized in table 1 . There is significant variation between studies, with up to a 10-fold range in the thickness of smooth muscle in airways of approximately the same size. This may be due to variations in: thickness within a bronchial segment (see below), subject size, sex, age, site sampled in the bronchial tree, and degree of muscle contraction, and possibly even racial differences.

\section{Orientation}

The airway smooth muscle encircles the airway completely below the level of the trachea (fig. 1). General descriptions of airway smooth muscle [1] have suggested that its orientation is transverse in the trachea and that it forms a helical or geodesic pattern around the central and peripheral airways. The angle of orientation may depend upon the degree of inflation of the lung, being more openmeshed at full inflation [1], which tends to maximize the angle of orientation. However, there are few quantitative studies. EBINA et al. [10] estimated that the angle of orientation was small, consistent with a circular orientation, in the central airways and approximately $30^{\circ}$ in the membranous bronchioles of lungs at full inflation. In a careful study using en face sectioning and orientating the airways by means of their own longitudinal bundles, LEI et al. [20] measured the angle between the long axes of the smooth muscle nuclei and the transverse plane of the airway. In a human lung, they found a mean angle of $13^{\circ}$, with a range of $-20-20^{\circ}$, similar to values obtained in cat lungs in the same study. Unlike the cat, there was less variation in the angles of orientation at the lung periphery. The studies of SPARROW and coworkers [21, 22], in which the airway smooth muscle was clearly identified using immunofluorescence and confocal microscopy, showed that, at least in foetal pigs, the airway smooth muscle assumes a predominantly transverse orientation in peripheral airways.

\section{The effects of age}

Matsuba and Thurlbeck [7] used point counting to measure the relative amounts of tissue constituents of the airway wall in infants, children and adults. In central airways, the airway smooth muscle content was $2.8 \%$ in children and similar at $2.6 \%$ in adults. In peripheral airways, the corresponding values were $10 \%$ in children 
and $14 \%$ in adults. SOBONYA [13] found values of $3-8 \%$ in central airways but no significant change from the age of 20 to 40 yrs. Hislop and HaWARTH [8] measured smooth muscle area using a digitizer in human subjects from 22 weeks gestational age to adulthood. They found that total muscle area and muscle area per millimetre of internal airway perimeter increased linearly from 22 weeks preterm to 8 months of age and increased between two and four-fold to early adulthood. In preliminary studies, it was found that, although the absolute amount of muscle in the airway wall was less in infancy, the relative area of smooth muscle was greater in infants compared with adults [23] and that there were no significant changes associated with ageing in adult life [24].

Therefore, airway smooth muscle is present and active in the normal foetal lung, encircles the entire airway below the level of the main bronchus, in roughly a circular orientation, except at high lung volumes, occupies relatively more of the airway wall in the peripheral airways and increases in absolute volume from infancy up to early adulthood with little change thereafter.

\section{Airway smooth muscle in disease}

\section{Asthma}

In 1922, Huber and Koessler [25] compared cross sections of large and small airways stained with haematoxylin and eosin from six patients who had died of asthma with seven cases without asthma who had died of nonrespiratory causes. They attempted to overcome some of the factors confounding measurement and comparison of airway smooth muscle area in different subjects. They normalized the area of smooth muscle by relating its thickness to the external diameter of the airway and noted that folding of the epithelial layer, evidence of smooth muscle contraction, showed no systematic variation between the two groups of subjects, that airways of the same size in the same individual showed marked variations in structures and that these variations were similar in their two groups. They acknowledged that differences in the numbers of measurements obtainable from different persons might unequally weight the results. They found that

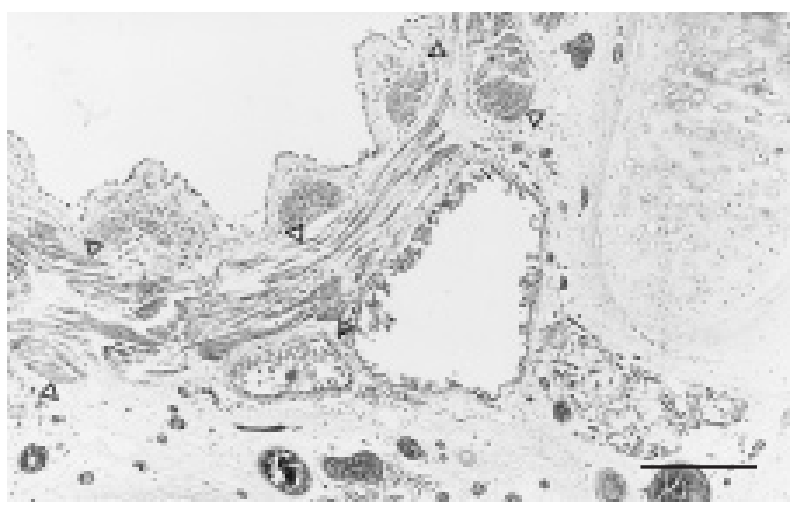

Fig. 2. - Marked hypertrophy/hyperplasia of smooth muscle in a large airway from a patient who died of asthma. The thickened band of smooth muscle (between arrowheads) shows some variation in orientation and clear areas representing intercellular matrix and/or oedema. The folding of the mucosa with prominent longitudinal bundles under the thickened sub-basement membrane suggests smooth muscle contraction. (Internal scale bar $=1 \mathrm{~mm}$.) the thickness of the muscle layer in patients with asthma was markedly increased (fig. 2) in all airway sizes except for airways with an outside diameter of $<1-2 \mathrm{~mm}$ and speculated regarding the relative contributions of hypertrophy and hyperplasia.

Two studies have systematically examined whether there is hyperplasia or hypertrophy of airway smooth muscle in patients with asthma. HEARD and Hossain [26] point counted all muscle in serial transverse sections $(10 \mu \mathrm{m})$ of posterior basal bronchus in cases of fatal asthma. Using the mean of two measurements, they found a three-fold difference between control cases (mean $0.50 \mathrm{~mm}^{2}$ ) and cases of asthma $\left(1.54 \mathrm{~mm}^{2}\right)$ with little overlap between the two groups. Hyperplasia was shown by an increased number of smooth muscle cell nuclei in asthmatics $(2,047)$ compared with control cases (717).

EBINA et al. [27] studied lungs from 16 patients with bronchial asthma and compared them with 20 control cases. The mean thickness of smooth muscle was plotted against airway radius on a logarithmic scale and was increased in all airway size groups in cases of asthma, compared with control cases. Further analysis of the distribution of muscular thickening in the asthmatic cases suggested that two distinct subgroups existed, one in which muscle hypertrophy was present only in the large airways (which they called type I cases), and one in which muscle hypertrophy was present both in large and small airways (type II cases). The same group [28] reported a more detailed study comparing airways from five control cases with those from 10 asthmatics, classified either as type I (muscle thickening in central bronchi only) or type II (muscle thickening along the entire bronchial tree). They used a three-dimensional sampling technique in which tracings of individual smooth muscle cells from 100-200 serial airway sections $(3 \mu \mathrm{m})$ were stacked to create a three-dimensional reconstruction of the sampled smooth muscle. The number of smooth muscle cell nuclei counted within the sampling area was multiplied by the length and width of the sampling frame to estimate smooth muscle cell number, and the sum of the individual smooth muscle cell areas was used in the same way to calculate the mean volume of a single smooth muscle cell and the volume of smooth muscle cells per section. They found that smooth muscle cell density increased and the mean volume of a single smooth muscle cell decreased towards the periphery of the bronchial tree. They also found a reduced number of smooth muscle cells per unit volume in smaller airways from type II asthmatics, corresponding to a greater mean single cell volume in airways of the same size, suggesting smooth muscle cell hypertrophy. Finally, they found that the number of smooth muscle cells in a unit length of an airway segment was greater in both types of asthma compared with control cases, suggesting that muscle cell hyperplasia also occurs.

SoBONYA [13] compared airway smooth muscle area in six cases of long-standing allergic asthma (fatal and nonfatal cases) with seven control cases in an autopsy study. Smooth muscle area was measured in transverse sections of matched central bronchi and airways from 10 stratified random sections of lung parenchyma. The mean percentage of muscle in the bronchi and the mean absolute area of muscle were greater in the asthma cases, although these differences were not statistically significant. 
DuNNILL et al. [12] point counted the area of smooth muscle in control cases, cases dying of status asthmaticus, cases of chronic bronchitis and cases of emphysema. Airway size was matched using the absolute number of points falling on cartilage. There was a $100 \%$ increase in the mean proportion of muscle in the airway wall in cases of asthma compared with control cases which were similar to cases of chronic bronchitis and emphysema. JAMES et al. [9] compared airway smooth muscle area in lungs from 17 cases of asthma with 23 control cases obtained at autopsy. Airways were grouped by size using the internal (epithelial) perimeter for comparison. With the exception of membranous bronchioles with a perimeter of $<2 \mathrm{~mm}$, the cases of asthma had significantly increased airway smooth muscle volume in all airway size groups. In the asthma cases, the increase in muscle area was approximately three-fold in medium-sized airways and two-fold in the largest cartilaginous airways.

TAKIZAWA and ThuRlBeck [6] examined sections from six matched central airways obtained at autopsy from each of three cases of fatal asthma, four cases of chronic bronchitis with episodes of wheezing during life ("asthmatic bronchitis") and seven cases of chronic bronchitis without wheezing. They found significantly more ( $70 \%)$ smooth muscle in the airway wall in cases of asthma compared with cases of chronic bronchitis, with cases of asthmatic bronchitis falling between these two groups.

CARROLl et al. [16] examined lungs obtained at autopsy from 11 cases of fatal asthma, 13 cases of nonfatal asthma and 11 control cases. The area of smooth muscle in the three case groups was compared in five airway size groups based on basement membrane perimeter. In cases of fatal asthma, the area of smooth muscle was increased in all airway size groups except the smallest membranous bronchioles, compared with control cases, and in the cartilaginous airways compared with nonfatal asthma cases. In cases of nonfatal asthma, the smooth muscle area was greater only in large membranous bronchioles, compared with control cases.

Unlike the approach of most other studies, THOMson et al. [29] examined longitudinal sections of airways from five cases of asthma, two undergoing surgical resection (one smoker) and three coming to autopsy (two deaths from asthma and one from nonrespiratory causes), and from five nonasthmatic individuals (all smokers or exsmokers) undergoing surgical resection for cancer. Circumferentially derived tissue strips were obtained from 2nd to 4th generation bronchi and longitudinal sections $(1.5 \mu \mathrm{m})$ were cut so that the smooth muscle fibres were oriented in cross section. Cross-sectional area, tissue width and basement membrane length were measured and the amount of smooth muscle, extracellular matrix and ribbons of connective tissue were point counted. They reported a $25 \%$ increase in smooth muscle area and a $50 \%$ increase in extracellular matrix area within the smooth muscle bundle in the cases of asthma.

In a study of small airways, KuwANO et al. [15] obtained lung specimens at autopsy from eight cases of fatal asthma and three cases of nonfatal asthma, and following surgical resection from four cases of nonfatal asthma, 15 patients with chronic airflow obstruction and 15 control cases. The square root of the smooth muscle area was plotted against the basement membrane perimeter and a regression line for each case group was constructed using a weighted analysis of each individual's regression data [30]. The slope of the regression line was significantly increased in asthma compared with control cases, showing that there was an increased amount of smooth muscle in all but the smallest (perimeter $<3 \mathrm{~mm}$ ) airways. The slope was also greater in fatal compared with nonfatal cases of asthma, and in nonfatal asthma compared with control cases. Overall, the smooth muscle thickness was two or three times greater in the airways of asthmatic subjects compared with controls.

In an autopsy study, SAETTA et al. [14] compared smooth muscle area in nonrespiratory bronchioles $(<2 \mathrm{~mm}$ internal diameter) from six cases of fatal asthma with six control cases. The amount of smooth muscle in the airway wall was scored semiquantitatively according to the method described by Cosio et al. [31], in which scores of zero (normal) to three (most abnormal) for the amount of muscle in all the bronchioles in each case are summed and expressed as a percentage of the maximum possible. They found that the score for muscle area in the asthmatic cases was increased three-fold compared with control cases.

Summary. Despite the variety of methods used to measure the amount of airway smooth muscle and express the results, there is consistency in the findings of quantitative studies comparing asthmatics with nonasthmatics. If each study is taken and the mean results in cases of asthma expressed as a percent of the mean results for nonasthmatic control cases, a mean value for all the studies can be derived, for a given airway size. These are summarized in table 2 [32]. In these studies, cases of nonfatal asthma were almost invariably of mild clinical severity and cases of fatal asthma almost invariably had a long history of severe symptoms and abnormal lung function. From table 2 , it can be seen that all studies show an increase in the amount of airway smooth muscle, the extent is greatest in fatal severe cases (fig. 2) and the increase in smoothmuscle amount is seen in all airway sizes. Other authors have not attempted to analyse subgroups as defined by EBINA et al. [28], although medium-sized airways seem to show the biggest differences between asthmatics and nonasthmatics.

\section{Methodology}

There are a number of sources of methodological variation to consider when interpreting the results from quantitative studies of airway smooth muscle. In no particular order of importance, these include tissue sampling, tissue processing, methods of quantitation and data analysis (table 3).

Table 2. - Smooth muscle area in cases of asthma relative to nonasthmatic cases

\begin{tabular}{|c|c|c|c|c|}
\hline & \multicolumn{2}{|c|}{$\begin{array}{l}\text { Membranous } \\
\text { airways }\end{array}$} & \multicolumn{2}{|c|}{$\begin{array}{l}\text { Cartilaginous } \\
\text { airways }\end{array}$} \\
\hline & Small & Large & Small & Large \\
\hline Fatal asthma & $\begin{array}{c}48 \\
(7-123)\end{array}$ & $\begin{array}{c}152 \\
(62-269)\end{array}$ & $\begin{array}{c}230 \\
(140-378)\end{array}$ & $\begin{array}{c}185 \\
(108-267)\end{array}$ \\
\hline Nonfatal asthma & $\begin{array}{c}25 \\
(14-36)\end{array}$ & $\begin{array}{c}162 \\
(83-108)\end{array}$ & $\begin{array}{c}43 \\
-\end{array}$ & $\begin{array}{c}50 \\
(44-55)\end{array}$ \\
\hline
\end{tabular}

Data are presented as mean (range) percentage increase. 
Table 3. - Sources of variation in studies of human airway smooth muscle

\begin{tabular}{|c|c|}
\hline Sampling & $\begin{array}{l}\text { Subject characteristics; disease characteristics; } \\
\text { site in the lung; matching airways }\end{array}$ \\
\hline $\begin{array}{l}\text { Tissue } \\
\text { preparation }\end{array}$ & $\begin{array}{l}\text { Lung inflation; immersion; fixatives; } \\
\text { embedding; cutting blocks; section thickness; } \\
\text { tissue orientation; histochemical and } \\
\text { immunohistochemical stains }\end{array}$ \\
\hline Measurement & $\begin{array}{l}\text { Point counting; digitizing; image analysis; } \\
\text { magnification; orientation; normalizing } \\
\text { (effects of contraction or lung inflation) }\end{array}$ \\
\hline Statistics & $\begin{array}{l}\text { Expression of results: } \%, \mathrm{~mm}^{2}, \mathrm{~mm}^{2} \cdot \mathrm{mm}^{-1}, \\
\mathrm{~mm}^{3} \text {; sample size; mean of means, averaging } \\
\text { or pooling data }\end{array}$ \\
\hline
\end{tabular}

\section{Tissue sampling}

Subject characteristics and the sites (central versus peripheral airways) selected, or available, for examination may influence the number of samples needed for adequate power to compare airway dimensions in groups of subjects. Using the formula of DoBson [33], the number of cases in each group necessary to detect differences between mean smooth muscle area in control and asthma cases can be calculated [34]. In large cartilaginous airways, 67 cases would need to be examined to detect a $50 \%$ difference and 16 cases to detect a $100 \%$ difference between two groups. For small noncartilaginous airways, these sample sizes need to be increased. Although many studies have shown significant differences between groups using smaller numbers (probably due to less variation between airways in a single case or less variation in measurements), studies in which small sample sizes are used (e.g. four to six cases) may not have sufficient statistical power to detect differences between patients with and without asthma.

Tissues obtained at autopsy, surgical resection or bronchial biopsy will vary in their usefulness (potential autolysis, airway sizes available, tissue sample size, presence of other disease, treatment effects, availability of subject details or physiological measures and availability of stains or markers suitable for the tissue obtained) for quantitative morphological assessment and comparison. The severity of the asthma influences the amount of muscle in the airway and this will contribute to the variability in studies in which severe and mild cases of asthma have been combined [9, 29]. Although the absolute volume of muscle increases with increasing airway size, the volume fraction of muscle in the airway wall decreases with increasing airway size. The need to compare airways of similar size necessitates some standard measure of airway size that is independent of the disease process, airway smooth muscle contraction and lung volume. The internal perimeter defined by the epithelial surface or, in its absence, the perimeter defined by the basement membrane seems best suited in this regard $[19,35]$. The studies of EBINA et al. [28] and HEARD and Hossain [26] show the variability of smooth muscle area along short segments of bronchus. Different tissue fixation techniques may result in variable amounts of tissue shrinkage. Given that the variations in shrinkage are probably random and occur in all tissues, it is not likely to be a significant problem when comparing groups using similar techniques, although must be corrected for when estimating absolute smooth muscle vol- ume. These numerous sources of variability make it virtually impossible to directly compare different studies. However, it is striking that, when groups of asthmatics and nonasthmatics are compared using identical techniques, the differences between them are similar across a large number of studies, as seen in table 2.

\section{Tissue preparation}

The study of THomson et al. [29] raises a number of important questions regarding tissue staining methods, the thickness of sections, the magnification at which they are measured and the orientation of the tissue section. Extracellular matrix proteins are found within smooth muscle bundles and these may be mistaken for smooth muscle cells using a histological stain such as haematoxylin and eosin, which differentiates poorly between muscle and nonmuscle tissue elements. This may lead to an overestimation of muscle cell volume, especially at lower magnifications, at which individual muscle fibres are less clearly defined. The advantage of using lower magnifications for measuring smooth muscle area is that the whole circumference of the airway wall is usually visible and thus smooth muscle bundles can be traced continuously. At higher magnifications, greater accuracy in determining the boundaries of smooth muscle bundles is possible, although the problem of overlapping high-power fields is a potential source of error. The Masson trichrome stain identifies connective tissue elements such as collagen separately from muscle fibres and the profile of smooth muscle is more clearly separated from those of connective tissue elements in airway sections which are cut in a longitudinal plane as opposed to a transverse plane.

\section{Chronic obstructive pulmonary disease and chronic bronchitis}

Following early studies which suggested that patients with emphysema [36] and chronic bronchitis [37] had more smooth muscle in their airways, a number of quantitative studies have examined the amount of airway smooth muscle in patients with chronic bronchitis (usual cough and sputum) with and without airflow obstruction, usually defined by a forced expiratory volume in one second (FEV1) below an arbitrary percentage of the predicted value. Smoking histories of subjects vary, as do methods of measuring smooth muscle, from semiquantitative scoring via point counting to semi-automated digitization of captured images.

The effects of smoking, in the absence of chronic obstructive pulmonary disease (COPD) or chronic bronchitis, have been examined in young smokers. Sobonya and KLEINERMAN [38] found that the percentage of the wall in central airways that was occupied by smooth muscle ranged from $3.5-8 \%$ in smokers (mean age 32 yrs) and controls (mean age 26 yrs) with no significant difference between the two groups. An earlier study [39] found no increase in scores for amounts of smooth muscle in the small airways of young smokers, compared with nonsmokers, although higher scores for inflammation were observed. Using similar methods, Cosio et al. [31] showed that higher scores for inflammation and for smooth muscle were present in older smokers; however, some of these patients had developed emphysema too, and fibrosis of the small airways was increased. 
HosSAIN and HEARD [40] showed that the area of smooth muscle was increased in transverse sections of segmental and subsegmental airways in patients with chronic bronchitis: $1.07 \mathrm{~mm}^{2}$ and $0.5 \mathrm{~mm}^{2}$, compared with 0.5 $\mathrm{mm}^{2}$ and $0.19 \mathrm{~mm}^{2}$ in control cases, and that the mean number of smooth muscle nuclei in sections of segmental airways was 1,793 in the bronchitics compared with 717 in the controls, consistent with hyperplasia as well as hypertrophy. Lung function was not measured in this group but was likely to be abnormal since three patients died of their condition. The same group did not find any difference in the amount of smooth muscle in the trachea of patients with chronic bronchitis [41]. DunNILl et al. [12] point counted the amount of smooth muscle in cartilaginous airways. They defined their cases of chronic bronchitis as those with usual cough and sputum without emphysema, although all of their cases had a history of "chronic airflow obstruction". In subjects with chronic bronchitis defined in this way, airway smooth muscle occupied $5.8 \%$ of the airway wall, similar to the percentage seen in subjects with emphysema $(5.5 \%)$ and not significantly different from that in control cases $(4.6 \%)$, but less than that found in cases of asthma (11.9\%). MulLEN et al. [42] studied small and large airways in patients with chronic bronchitis who had normal lung function. They found that the relative area of smooth muscle increased towards the peripheral airways in cases and control subjects (see above) with no significant differences between the groups for any airway size. The overall mean for chronic bronchitis was $2.4 \%$ and for controls was $2.0 \%$. Very little inflammation of the smooth muscle was observed. Nagai et al. [43] studied lung specimens from cases with moderate-to-severe airflow obstruction (mean FEV1 of $31 \%$ pred) from the National Institute of Health Intermittent Positive Pressure Breathing Trial. Compared with controls, the cases had more emphysema, narrower bronchioles, decreased amounts of cartilage, an enlarged mucous gland area and increased scores for inflammation. They found that there tended to be more smooth muscle in the younger subjects, although this was nonsignificant. The calculated volume proportion of smooth muscle in central and peripheral airways was 4.6 and $8.5 \%$ in the COPD patients, significantly greater than the 2.8 and $5.8 \%$ in the control cases. MATSUBA and THuRlBeck [44] found that, in patients with bronchitis, the relative area of smooth muscle in large and small airways was 3.3 and $9.5 \%$ respectively, compared with 2.6 and $14 \%$ in normal subjects.

A number of studies [15, 17, 45] from the Vancouver group have systematically examined the dimensions of large and small airways from smokers with and without airflow obstruction and from cases of asthma. They plotted the square root of the airway smooth muscle area against airway size, defined by the basement membrane perimeter seen on transverse sections. The constant and the coefficient for the linear equation give the overall difference between case groups and the degree to which they vary according to airway size. Bosken et al. [45] compared the dimensions of small airways $(<2 \mathrm{~mm}$ diameter) from 30 smokers without airflow obstruction (45 pack-yrs, FEV1 $77 \%$ pred) with those from 30 smokers with airflow obstruction (70 pack-yrs, FEV1 55\% pred). They showed that the airway walls were thicker in subjects with obstruction. Although the percentage of the inner airway wall occupied by smooth muscle was not different between the two groups, the area of smooth muscle (in $\mathrm{mm}^{2}$ ) was increased in the obstructed group (intercept 0.0561 , slope 0.1398 ) compared with the control group (intercept 0.0495, slope 0.1244). KuWANO et al. [15] undertook a similar analysis in membranous airways (perimeter $<10 \mathrm{~mm}$ ) in subjects with mild airflow obstruction (FEV $1<85 \%$ pred, mean $69 \%$ pred, compared with $96 \%$ pred for controls) and found the airway smooth muscle area was increased in the obstructed group (intercept 0.016 , slope 0.035 ) compared with the control group (intercept 0.056, slope 0.020), significant for slope only. These values were significantly lower than those for fatal and nonfatal asthmatics. TidDens [17] studied cartilaginous airways from 72 subjects with varying degrees of airflow obstruction (FEV1 58-135\% pred). Using multiple linear regression analysis, they did not find a significant correlation between the slope or intercept of the regression line of smooth muscle area on airway perimeter and measures of airway function or of peripheral airway inflammation. The slope (0.020) and intercept $(0.230)$ were the same for subjects with a mean $\mathrm{FEV} 1$ of $40 \%$ pred and for those with a mean FEV1 of $80 \%$ pred.

Summary. In smokers with or without chronic bronchitis but without airflow obstruction, there do not seem to be any significant differences in the amount of airway smooth muscle present in large and small airways. Conversely, in subjects with measurable airflow obstruction or a history suggesting severe airflow obstruction, the amount of airway smooth muscle is increased in large and small airways in most, but not all [17], studies. The differences are much less than those observed in asthma.

\section{Other airway diseases}

Few quantitative studies have been undertaken in diseases other than those mentioned above. ELLIOT et al. [46] showed that the area of smooth muscle was increased in small airways in cases of sudden infant death syndrome compared with control cases. In the study of HisLOP and HAWORTH [8], premature infants had more smooth muscle in small cartilaginous airways compared with control cases of comparable postconceptual age. This difference was greatest in infants who were ventilated. Bronchiectasis, including cystic fibrosis, is an airway disease associated with intense airway inflammation, but there are no reported studies which have quantified the amount of smooth muscle present in the airway wall in this condition.

\section{The relationship between airway structure and function}

Although the role of smooth muscle in the airway remains in the realm of conjecture, it certainly causes variation in airway calibre and airway wall compliance, and contraction of airway smooth muscle is almost certainly necessary for the excessive airway narrowing that is observed in asthma (see below). Its importance in other diseases such as COPD and chronic bronchitis is probably less since airflow obstruction is fixed and administration of inhaled bronchoconstrictors results in only limited smooth muscle shortening, unlike that seen in asthma. In asthma, the sudden and intermittent nature of airway narrowing and 
the response of the symptoms to smooth muscle agonists and antagonists have given rise to the suggestion that abnormalities of airway smooth muscle may be the primary abnormality. The mechanisms involved are not clear. As shown above, the amount of smooth muscle is increased; however, consistent differences in smooth muscle function in vitro between asthmatic and nonasthmatic subjects have not been demonstrated. Most studies have not shown any correlation between in vivo and in vitro airway responsiveness [47-49]. Smooth muscle from cases of asthma has been shown to exhibit reduced responsiveness to smooth muscle relaxants in some studies $[50,51]$, with only isolated cases reporting increased responses to agonists in vitro. These studies are confounded by difficulties in normalizing for the amount and length/tension properties of the smooth muscle.

MoReno et al. [52] hypothesized a number of mechanisms by which excessive airway narrowing might occur in vivo, including alterations in smooth muscle behaviour, amount or orientation, or loss of factors inhibiting maximal smooth muscle shortening, as proposed by MACKLEM [53]. The same group demonstrated that excessive shortening of smooth muscle may not be required if it contracts around an airway which has a thicker wall than normal, as seen in asthma [9], and the addition of mucus to the lumen magnifies these effects [54]. More sophisticated modelling has shown that alterations in airway wall thickness in the peripheral airways will have greater effects than in the central airways, that similar, though less pronounced, changes in the airway wall in COPD will have similar effects [55] and that thickening of the outer part of the airway wall will also exaggerate the effects of smooth muscle shortening on airway narrowing [56].

Modelling of the effects of muscle orientation has also been undertaken [57], although the data presented above suggest that, at lung volumes close to functional residual capacity, the angle of orientation is small.

Increased airway wall thickness involves all of the components in this compartment, including luminal mucus, the epithelium, the submucosa, blood vessels, submucosal mucous glands and airway smooth muscle $[32,58,59]$. Since the smooth muscle contributes relatively more to the thickness of the airway wall in the peripheral airways, the effects of smooth muscle hypertrophy and hyperplasia may be expected to be greater in the smaller airways. One analysis suggests that an increase in the amount of muscle will have the greatest effects on maximal narrowing in asthma, especially in small airways [60].

Three important points arise from these studies. Firstly, it is assumed that smooth muscle is maximally stimulated during in vivo inhalational challenge. This is yet to be proven. Second, it is assumed that the force-generating properties of the smooth muscle are not changed in asthma. There are conflicting in vitro data, as shown above, and smooth muscle undergoing hyperplasia may be phenotypically and functionally altered. Finally, despite all of the above concerns, it must be remembered that the clinical, in vivo, in vitro and modelling evidence all demonstrate that at least some smooth muscle shortening must occur to produce the excessive airway narrowing that is seen in asthma. It seems unlikely that the thickening of the airway wall, increased thickness of the smooth muscle, increased numbers of blood vessels [58] or increased luminal mucus
[54] will, by themselves or even in combination, result in excessive airway narrowing in the absence of smooth muscle shortening.

\section{Relationship of airway smooth muscle and airway inflammation}

The other characteristic of airway diseases is inflammation. In chronic obstructive pulmonary disease this consists predominantly of lymphocytes and neutrophils [61] and in asthma predominantly of lymphocytes and eosinophils $[34,62]$, although the relative numbers of neutrophils and eosinophils may vary in both conditions $[62,63]$. However, these inflammatory cells may be less important than mast cells in determining airway smooth muscle function. It has recently been shown that mast cells are more common in smooth muscle that is sensitized to allergen [64] and preliminary work shows that, in asthmatic and nonasthmatic tissue, mast cells are the predominant inflammatory cell in airway smooth muscle [65]. The relative importance of the release of inflammatory cytokines, mediators and growth factors from these and other cells are yet to be determined.

\section{References}

1. Macklin CC. The musculature of the bronchi and lungs. Physiol Rev 1929; 9: 1-60.

2. Reisseisen FD. Uber den Bau der Lungen. Berlin, 1822.

3. Grancher J. Maladies de l'appareil respiratoire. In: Tuberculose et auscultation. Lecons cliniques recueilles par le Dr L. Faisans. Paris, 1890.

4. Miller WSW. The musculature of the finer divisions of the bronchial tree and it's relation to certain pathological conditions. Am Rev Tuber 1921; 5: 689-704.

5. von Hayek H. The Human Lung. Hafner Publishing Company Inc., New York, 1960; pp. 139-144.

6. Takizawa T, Thurlbeck WM. Muscle and mucous gland size in the major bronchi of patients with chronic bronchitis, asthma, and asthmatic bronchitis. Am Rev Respir Dis 1971; 104: 331-336.

7. Matsuba K, Thurlbeck WM. A morphometric study of bronchial and bronchiolar walls in children. Am Rev Respir Dis 1972; 105: 908-913.

8. Hislop AA, Haworth SG. Airway size and structure in the normal foetal and infant lung and the effect of premature delivery and artificial ventilation. Am Rev Respir Dis 1989; 140: $1717-1726$.

9. James AL, Pare PD, Hogg JC. The mechanics of airway narrowing in asthma. Am Rev Respir Dis 1989; 139: 242-246.

10. Ebina M, Yaegashi H, Takahashi T, Motomiya M, Tanemura M. Distribution of smooth muscles along the bronchial tree. Am Rev Respir Dis 1990; 141: 1322-1326.

11. Hale FC, Olsen CR, Mickey MRJ. The measurement of bronchial wall components. Am Rev Respir Dis 1968; 98: 976-987.

12. Dunnill MS, Massarella GR, Anderson JA. A comparison of the quantitative anatomy of the bronchi in normal subjects, in status asthmaticus, in chronic bronchitis, and in emphysema. Thorax 1969; 24: 176-179.

13. Sobonya R. Quantitative structural alterations in long-standing allergic asthma. Am Rev Respir Dis 1984; 130: 289-292.

14. Saetta M, Di Stefano A, Rosina C, Thiene G, Fabbri LM. Quantitive structural analysis of peripheral airways and arteries in sudden fatal asthma. Am Rev Respir Dis 1991; 143: 138-143.

15. Kuwano K, Bosken CH, Pare PD, Bai TR. Small airways dimensions in asthma and in chronic obstructive pulmonary disease. Am Rev Respir Dis 1993; 148: 1220-1225.

16. Carroll NG, Elliot J, Morton AR, James AL. The structure of large and small airways in nonfatal and fatal asthma. Am Rev Respir Dis 1993; 147: 405-410. 
17. Tiddens HAWM, Pare PD, Hogg JC, Hop WCJ, Lambert R. Cartilaginous airway dimensions and airflow obstruction in human lungs. Am J Respir Crit Care Med 1995; 152: 260-266.

18. James AL, Hogg JC, Dunn LA, Pare PD. The use of the internal perimeter to compare airway size and to calculate smooth muscle shortening. Am Rev Respir Dis 1988; 138: 136-139.

19. James AL, Pare PD, Hogg JC. Effects of lung volume bronchoconstriction, and cigarette smoke on morphometric airway dimensions. J Appl Physiol 1988; 64: 913-919.

20. Lei M, Ghezzo H, Chen MF, Eidelman DH. Airway smooth muscle orientation in intraparenchymal airways. $J \mathrm{Appl}$ Physiol 1997; 82: 70-77.

21. Sparrow MP, Mitchell HW. Contraction of smooth muscle of pig airway tissues from before birth to maturity. $J \mathrm{Appl}$ Physiol 1990; 68: 468-477.

22. Sparrow MP, Warwick SP, Mitchell HW. Foetal airway motor tone in prenatal lung development of the pig. Eur Respir $J$ 1994; 7: 1416-1424.

23. James AL, Christmas T. Mechanisms of bronchial hyperresponsiveness in infants. Am Rev Respir Dis 1989; 139: A106.

24. James A, Elliot J, Carroll N. Airway structure and the aging lung. In: New Horizons in Aging Science. Proceedings of the Fourth Asia/Oceania Regional Congress of Gerontology. University of Tokyo, 1992; pp. 172-173.

25. Huber HL, Koessler KK. The pathology of bronchial asthma Arch Intern Med 1922; 30: 689.

26. Heard BE, Hossain S. Hyperplasia of bronchial muscle in asthma. J Pathol 1973; 110: 319-331.

27. Ebina M, Takahashi T, Chiba T, Motomiya M. Cellular hypertrophy and hyperplasia of airway smooth muscles underlying bronchial asthma. Am Rev Respir Dis 1993; 148: 720-726.

28. Ebina M, Yaegashi H, Chiba R, Takahashi T, Motomiya M, Tanemura M. Hyperreactive site in the airway tree of asthmatic patients revealed by thickening of bronchial muscles. Am Rev Respir Dis 1990; 141: 1327-1332.

29. Thomson RJ, Bramley AM, Schellenberg RR. Airway muscle stereology: implications for increased shortening in asthma. Am J Respir Crit Care Med 1996; 154: 749-757.

30. Feldman HA. Families of lines: random effects in linear regression analysis. J Appl Physiol 1988; 64: 1721-1732.

31. Cosio MG, Hale KA, Niewoehner DE. Morphologic and morphometric effects of prolonged cigarette smoking on the small airways. Am Rev Respir Dis 1980; 122: 265-271.

32. James AL. Relationship between airway wall thickness and airway hyperresponsiveness. In: Stewart AG, ed. Airway Wall Remodelling in Asthma. New York, CRCPress, 1997;pp. 1-27.

33. Dobson AJ. Calculating sample size. Trans Menzies Found 1984; 7: 75-79.

34. Carroll NG, Lehman E, Barret J, Morton AR, Cooke C, James AL. Variability of airway structure and inflammation in normal subjects and in cases of nonfatal and fatal asthma. Path Res Pract 1996; 192: 238-248.

35. James AL, Lougheed D, Pearce-Pinto G, Ryan G, Musk AW Maximal airway narrowing in a general population. Am Rev Respir Dis 1992; 146: 895-899.

36. Lenart E. Beobachtungen über das Verhalten der glatten Muskulatur der kleineren Luftwege bei verschiedenen Erkrankungen. Zentralbl allg Path path Anat 1923-1924; 34: 202.

37. Leibow AA, Loring WE, Felton WL. The musculature of the lungs in chronic pulmonary disease. Am J Pathol 1953; 29: 885-912.

38. Sobonya RE, Kleinerman J. Morphometric studies of bronchi in young smokers. Am Rev Respir Dis 1972; 105: 768-775.

39. Niewoehner DE, Kleinerman J, Rice DB. Pathologic changes in the peripheral airways of young cigarette smokers. $N$ Engl J Med 1974; 291: 755-758.

40. Hossain S, Heard BE. Hyperplasia of bronchial muscle in chronic bronchitis. J Pathol 1970; 101: 171-184.

41. Macleod LJ, Heard BE. Area of muscle in tracheal sections in chronic bronchitis, measured by point-counting. J Pathol 1968; 97: 157-161.

42. Mullen JBM, Wright JL, Wiggs BR, Pare PD, Hogg JC
Reassessment of inflammation of airways in chronic bronchitis. BMJ 1985; 291: 1235-1239.

43. Nagai A, West WW, Paul JL, Thurlbeck WM. The National Institutes of Health intermittent positive-pressure breathing trial:pathology studies. Am RevRespir Dis 1985; 132:937-945.

44. Matsuba K, Thurlbeck WM. Disease of the small airways in chronic bronchitis. Am Rev Respir Dis 1973; 107: 552-558.

45. Bosken $\mathrm{CH}$, Hards J, Gatter K, Hogg JC. Characterization of the inflammatory reaction in the peripheral airways of cigarette smokers using immunocytochemistry. Am Rev Respir Dis 1992; 145: 911-917.

46. Elliot J, Vullermin P, Carroll N, James A, Robinson P. Increased airway smooth muscle in sudden infant death syndrome. Am J Respir Crit Care Med 1998; 158: 802-806.

47. Armour CL, Lazar NM, Schellenberg RR. A comparison of in vivo and in vitro human airway reactivity to histamine. Am Rev Respir Dis 1984; 129: 907-910.

48. Cerrina J, Le Roy Ladurie M, Labat C, Raffestin B, Bayol A, Brink C. Comparison of human bronchial muscle responses to histamine in vivo with histamine and isoproterenol agonists in vitro. Am Rev Respir Dis 1986; 134: 57-61.

49. Vincenc KS, Black JL, Yan K, Armour CL, Donnelly PD, Woolocock AJ. Comparison of in vivo and in vitro responses to histamine in human airways. Am Rev Respir Dis 1983; 128: 875-879.

50. de Jongste JC, Mows H, Bonta IL, Kerrebijn KF. Human asthmatic airway responses in vitro. Eur J Respir Dis 1987; 70: 23-29.

51. Goldie RG, Spina D, Henry PJ, Lubich KM, Patterson JW. In vitro responsiveness of human asthmatic bronchus to carbachol, histamine, $\beta$-adrenoceptor agonist and theophylline. Br J Clin Pharmacol 1986; 22: 669-676.

52. Moreno RH, Hogg JC, Pare PD. Mechanics of airway narrowing. Am Rev Respir Dis 1986; 133: 1171-1180.

53. Macklem PT. Bronchial hyperresponsiveness. Chest 1985; 87: $158 \mathrm{~S}-159 \mathrm{~S}$

54. James AL, Carroll NC. Theoretic effects of mucus gland discharge on airway resistance in asthma. Chest 1995; 107: 110S.

55. Wiggs BR, Bosken C, Pare PD, James AL, Hogg JC. A model of airway narrowing in asthma and in chronic obstructive pulmonary disease. Am Rev Respir Dis 1992; 145: 1251-1258.

56. Pare PD, Wiggs BR, James AL, Hogg JC, Yaegashi H, Pare $\mathrm{PD}$. The comparative mechanics and morphology of airways in asthma and in chronic obstructive pulmonary disease. Am Rev Respir Dis 1991; 143: 1182-1189.

57. Bates JHT, Martin JG. A theoretical study of the effect of airway smooth muscle orientation on bronchoconstriction. $J$ Appl Physiol 1990; 69: 995-1001.

58. Carroll NG, Cooke C, James AL. Bronchial blood vessel dimensions in asthma. Am J Respir Crit Care Med 1997; 155: 689-695.

59. James AL, Carroll NG. The pathology of fatal asthma. In: Holgate ST, Busse WT, eds. Inflammatory Mechanisms in Asthma. New York, Marcel Dekker Inc., 1998; pp. 1-26.

60. Lambert RK, Wiggs BR, Kuwano K, Hogg JC, Pare PD. Functional significance of increased airway smooth muscle in asthma and COPD. J Appl Physiol 1993; 74: 2771-2781.

61. Saetta M. Central airways inflammation in the development of COPD. Eur Respir Rev 1997; 7: 109-110.

62. Carroll NG, Carello S, Cooke C, James A. Airway structure and inflammatory cells in fatal attacks of asthma. Eur Respir $J$ 1996; 9: 709-715.

63. Saetta M, Di Stefano A, Maestrelli P, et al. Airway eosinophilia in chronic bronchitis during exacerbations. Am J Respir Crit Care Med 1994; 150: 1646-1652.

64. Ammit AJ, Bekir SS, Johnson PR, Hughes JM, Armour CL, Black JL. Mast cell numbers are increased in the smooth muscle of human sensitised isolated bronchi. Am J Respir Crit Care Med 1997; 155: 1123-1129.

65. James AL, Carroll NG. Mast cells and neutrophils in the airway wall in asthma. Am J Respir Crit Care Med 1998; 157: A873. 